\title{
Correction to: Patient-Reported Outcomes of Video-Assisted Thoracoscopic Surgery Versus Thoracotomy for Locally Advanced Lung Cancer: A Longitudinal Cohort Study
}

\author{
Xing Wei, $\mathrm{MD}^{1}$ (D), Hongfan Yu, BSc ${ }^{2}$, Wei Dai, $\mathrm{MD}^{1}$ (D), Yunfei Mu, $\mathrm{MD}^{3}$, Yaqin Wang, $\mathrm{RN}^{1}$, \\ Jia Liao, RN ${ }^{1}$, Lin Peng, MD ${ }^{1}$, Yongtao Han, MD ${ }^{1}$, Qiang Li, MD ${ }^{1}$, and Qiuling Shi, $\mathrm{MD}^{2,4}$ (]) \\ ${ }^{1}$ Department of Thoracic Surgery, Sichuan Cancer Hospital and Institute, Sichuan Cancer Center, School of Medicine, \\ University of Electronic Science and Technology of China, Chengdu, Sichuan, China; ${ }^{2}$ School of Public Health and \\ Management, Chongqing Medical University, Chongqing, China; ${ }^{3}$ Department of Thoracic Surgery, Chengdu Third \\ People's Hospital, Chengdu, Sichuan, China; ${ }^{4}$ Center for Cancer Prevention Research, Sichuan Cancer Hospital, School of \\ Medicine, University of Electronic Science and Technology of China, Chengdu, Sichuan, China
}

\section{CORRECTION TO: ANN SURG ONCOL}

HTTPS://DOI.ORG/10.1245/S10434-021-09981-1

Figure 1 was incorrect in the original online version of this article. The original article has been corrected.
Publisher's Note Springer Nature remains neutral with regard to jurisdictional claims in published maps and institutional affiliations.

The original article can be found online at https://doi.org/10.1245/ s10434-021-09981-1.

(C) Society of Surgical Oncology 2021

Published Online: 24 September 2021

Q. Shi, MD

e-mail: qshi@cqmu.edu.cn 